\title{
Driving Engines Effect on Settlement Patterns and Efficiency of the Settlement Influence at Al-Za'atari Camp
}

\author{
Majd Al-Homoud ${ }^{1,2}$ \& Ola Samarah ${ }^{2}$ \\ ${ }^{1}$ Department of Architecture, Prince Sultan University, Riyadh, KSA \\ ${ }^{2}$ School of Architecture, German Jordanian University, Amman, Jordan \\ Correspondence: Prof. Dr. Majd Al-Homoud, Department of Architecture, Prince Sultan University, Riyadh, KSA, \\ P.O. Box 66833, Riyadh 11586, KSA.E-mail: mhomoud@psu.edu.sa; majd.alhomoud@gju.edu.jo
}

\author{
Received: January 4, $2022 \quad$ Accepted: February 6, $2022 \quad$ Online Published: February 8, 2022 \\ doi:10.5539/jsd.v15n2p78 URL: https://doi.org/10.5539/jsd.v15n2p78
}

\begin{abstract}
As refugees lose their sense of spatial identity, they try to adapt by recreating their lost community through revival of rituals, religion, defense, lifestyle, prestige, and climate. Population displacement theory deals with settlements as form of socio-cultural action. The study the driving engines behind the shifted emerging patterns and their influence on the efficiency of the settlement at Al-Za'atari Syrian Refugee Camp, in North Jordan, Al-Mafraq. Face-to-face interviews with camp mobilizers explored the driving engines behind the shifted settlement patterns, and its influence on mobilizers' reachability. A cluster stratified random sample was used to collect quantitative data through a structured questionnaire. Outcomes indicated that refugees are gradually transforming the formal public spaces at the cluster level to private ones as an extension to the shelter domain. Such spatial shifts appear to be driven by a combination of physical, social, socio-spatial drivers, and past socio-spatial experience. These spatial shifts from the formal grid are influenced by refugees' social values and territorial behavior, expressing zones of influence as means of defensive adaptation. Statistical analysis attested the influence of driving engines on settlement patterns and on the efficiency of the settlement. The driving engines behind the spatial shifts are safety concerns, cultural concerns, religious reasons, lifestyle, prestige, ethnicity and origin, improved infrastructure, improved access to services, and micro-climate. Such attributes influence the total efficiency of the settlement. Conclusively, planners should consider socio-cultural values that reflect defensibility, boundaries definition, and interdependence.
\end{abstract}

Keywords: refugees, spatial, sustainable, socio-cultural, planning, Jordan

\section{Introduction}

With the escalation of the Syrian crisis in 2011 and the ongoing disputes that remain locked in a stalemate, expanding numbers of Syrians are seeking refuge in neighboring countries including Jordan. Al-Za'atari Camp has emerged in Al-Mafraq as a quick response to the sudden influx of refugees to the Kingdom. Statistics show that 618,615 Syrians sought asylum there in 2014 . However, only $20 \%$ of them are staying at the camp, as the majority moved to Jordanian urban-based communities, with some of them leaving legally but the majority illegally (Bonnin, 2012; UNHCR, 2014).

The Arab World witnessed divergent population displacements under the rubric of Arab Spring. One of the multitude methodological applications to comprehensively analyze the conceptual framework of population displacement, is to grasp its multiple causes and multidimensional consequences. As a coping mechanism following the large and unpredictable in-flow of refugees, many refugee camps emerged in some Arab States. It is the United Nations High Commissioner for Refugees (UNHCR) that plays the leading role in registering refugees, and planning and managing their camps. Its staff try to support refugees in their times of hardship, allow them to regain what they have lost in some form, and help them overcome the hurdles they face (Barutciski, 2009; Shami, 1994, 1993; UNHCR, 2014).

Earlier research tended to study the conception of displacement as a one-shot community issue. Nevertheless, it should be studied with inclusion of its multi-dimensions by considering causes, consequences, and the particularities of each experience as a process on its own. Planning a refugee camp usually ignores the sociocultural specificity of each case (Corsellis \& Vitale, 2005; Shami, 1993; Scudder et al., 1982; Woods, 1982). In 
such exceptions, settlements and resources management are highly influenced by the spatial context. Articulating the social structure of displaced communities is important, for it has a key role in weaving the spatial pattern (Corsellis et al., 2005; Rapoport, 1969). Accordingly, the significance of this study lies behind its scope to explore the settlement patterns of Al-Za'atari Camp, within its socio-cultural context. It further tests attributes that potentially affect the efficiency of the settlement and mobilizers' reachability to settlers.

Since the foundation of Al-Za'atari Camp, UNHCR planners adjusted the spatial pattern on a grid base without consideration for refugees' socio-cultural background. The grid plan is the easiest and fastest spatial pattern to implement, especially in the cases of humanitarian disasters, when quick and immediate actions are needed in the middle of chaos. Camp planners utilize the grid plan for security reasons as well, to avoid clustered plans that would be controlled by influential groups of refugees (Bonnin, 2012; Corsellis et al., 2005). However, refugees shifted the grid pattern and created clustered social spaces. The argument made here is that what are those emerging spatial settlement patterns, and whether the grid versus the shifted-from-grid patterns have influences on the efficiency of the camp reflected by mobilizers' reachability to the settlers.

Attention of the study is drawn to the situation of Syrian refugees' displacement, examining the different sociocultural facets of the phenomenon. The specific objectives of the study include:

Explore the emerging spatial settlement patterns that shifted from the planned grid to a clustered pattern at AlZa'atari Camp.

1) Explain the driving engines that caused such emerging spatial shifts.

2) Identify influence of the driving engines on mobilizers' reachability that reflects the efficiency of the settlement.

3) Identify the influence of the driving engines on the total efficiency of the settlement.

The study is one of the very few scientific works that examine the socio-cultural context of displaced communities especially in the case of Al-Za'atari Camp, as it plays a key role in redirecting the physical planning context. It highlights the planning gaps that are related to refugees' unmet socio-cultural needs, as this allows camp officials and mobilizers enhance the performance of the settlement. It is hoped that the study adds knowledge concerning the field of population displacement, and contributes towards planning more efficient settlements to refugees, especially that on average a refugee camp stays for twenty years.

After a review of relevant published literature, simultaneously, the quantitative data were collected and analyzed. The research method introduced elaborated answers to the raised research questions, therefore, allowing better understanding of the phenomena in terms of the emerging settlement patterns and their influence on the efficiency of the settlement.

The hypotheses of the present study are: (1) Settlement patterns at Al-Za'atari Camp are affected by physical and socio-cultural driving engines. The physical driving engines include improved access to services, improved infrastructure, and micro-climate, while the socio-cultural driving engines include safety concerns, cultural concerns, religious reasons, lifestyle, prestige, and ethnicity and origin. (2) Efficiency of the settlement is affected by physical and socio-cultural driving engines at $\mathrm{Al}-\mathrm{Za}$ 'atari Camp. The physical driving engines include improved access to services, improved infrastructure, and micro-climate, while the socio-cultural driving engines include safety concerns, cultural concerns, religious reasons, lifestyle, prestige, and ethnicity and origin.

A structured questionnaire consisting of closed-ended questions was administered. It was divided into four sections: personal information, morphological settlement pattern of the cluster, driving engines, and efficiency of settlement. A stratified cluster sampling technique was used to select the sample. Stratification was for representation of each cluster in the assigned six districts. Four subjects were selected from each of the (117) clusters that existed in the six investigated districts.

\subsection{Research Setting}

With the escalation of the Syrian crisis since 2011, many Syrians fled their homes and sought refuge in Jordan. In a quick response to the massive influx of Syrian refugees into Jordan; the Jordanian government decided on July 28, 2012 to accelerate the construction of Al-Za'atari camp, see figure 1 (ACTED, 2014; UNHCR, 2014, 2015).

The camp is located near Al-Mafraq city in north Jordan, about 12km away from the Syrian border (ACTED, 2014; UNHCR, 2014, 2015). Al-Zaatari camp emerged on a desert tract in Al-Mafraq Governorate in north Jordan, with a total area of $5.02 \mathrm{~km}^{2}$. Around 86,040 refugees are settling at the camp in 2015. UNHCR, along with a group of NGOs, are mainly in charge of the camp's management and planning. Refugees have free access to medical services, and are provided with infrastructure, food, and education. The old camp area consisted of districts one, 
two, three, four, and twelve, which received the first waves of refugees was totally chaotic as refugees shifted themselves from the provided grid pattern as a reflection to their higher sense of safety and security. Over time, refugees were spatially controlled in the formally planned grid, mainly in districts five, six, seven, eight, nine, ten, and eleven. Of the twelve districts of the camp, six districts (five, six, seven, eight, nine, and ten) are covered in this study.

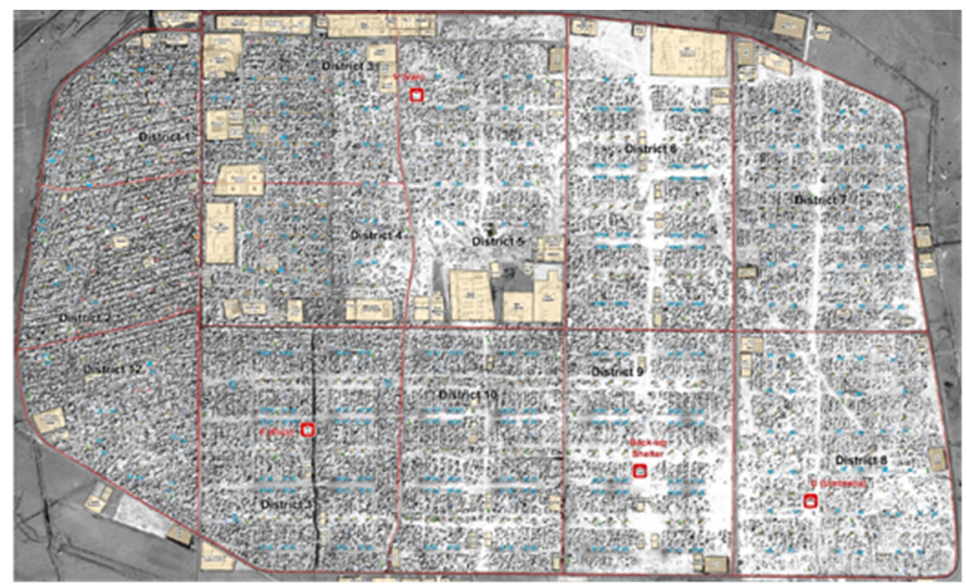

Figure 1. Al-Za'atari camp map

Source: UNHCR, 2015.

The Jordanian Armed Forces took control until mid-January 2012 over the security issues. Afterwards, the camp became managed jointly by UNHCR and the Jordanian Government. However, since March 2012, the management of the camp was moved to UNHCR. The camp has two check points manned by Jordanian police and Gendarmerie to control the entrances. After the Jordanian Syrian borders were closed, Syrians started crossing the borders illegally to go to Al-Za'atari camp. Some of them stay at the camp, while others left legally or illegally to Jordanian urban settings, to rejoin other family members or for security reasons (ACTED, 2014; UNHCR, 2014).

More than $42 \%$ of the total Syrian refugees in Jordan reside in Al-Mafraq in North Jordan. Despite the difficulties in getting exact figures of total Syrian refugees in Jordan, due to the large numbers of them who crossed the Jordanian borders illegally, Al-Za'atari population reached 86,040 refugees by the end of October 2014. The population at Al-Za'atari Camp included 24,493 families and 17,494 households. The average household size is 6.58 , and in each household, there is an average of 1.38 families (UNHCR, 2014). About 90-92\% of the camp's population originate from Dara'a in Huran in South Syria. The female population at the camp makes $50.5 \%$ of the total population. In general, $40.3 \%$ of Syrian refugees are aged 18 to 59 years (ACTED, 2014; UNHCR, 2014).

Number of refugees is increasing in most of Jordanian governorates, which explains the population decline at AlZa'atari Camp. Statistics show that only $20 \%$ of the total refugees in Jordan are staying at the camp. In Mafraq Governorate, refugees reached 76,685, in Zarqa Governorate 52,074, and in Irbid Governorate (also near Huran) there are 144,070 (ACTED 2014; UNHCR, 2014).

\subsection{Literature Review}

The review mainly addresses works related to population displacement theory, informal and formal patterns of displacement, planning issues, physical layout, socio-cultural influences, defensible space theory, in addition to selected case studies in Jordan

\subsubsection{Population Displacement Theory}

Researchers pay attention to the concept of population displacement as a whole process. Population displacement was initially introduced by a group of researchers as a collective change of location from the place of origin by superior forces directly or indirectly. It could be permanent or temporary, voluntary, or involuntary, and can be done individually or in groups. The displaced could be tied together sometimes as kin, communities on notions of ethnicity or politics, or through shared cultural heritage (Hansen et al., 1968; Shami, 1990; UNHCR, 2002). Population displacement should be viewed as a phenomenon that needs exploration and explanation rather than dealing with a temporary stage of policies or temporary development projects. Displacement theories mostly deal with the causes and effects (Cernea et al, 2000; Shami, 1993; Woods; 1982). Agents of displacement are mainly development projects, war or political upheaval, and natural disasters. Whatever the reason behind displacement 
is, similar consequences befall refugees (Cernea et al, 2000; Loizos, 1981; Olson, 1979; Shami, 1993, 1994).

It is believed that the push-pull forces behind population displacement and its consequences are mainly behavioral, where individuals seek to maximize their life-chances (Hansen \& Butzer, 1968; Shami, 1993; Woods, 1982). Protection and security are one main reason behind political population displacement. On the one hand, safety and psychological needs are fundamental for humans and take precedence in crisis or insecurity situations. In such cases, lack of protection in the country-of-origin forces people to seek other sources of protection, within or across their homeland borders (Bajpai, 2000; Barutciski, 2009; NRC, 2009). The forces that lead to displacement, such as insecurity, continuously inform the resettlement, which causes some changes on refugees' community patterns and may generate difficulties in adapting to the new altered situation (Corsellis \& Vitale, 2005; NRC, 2009; Shami, 1993).

Population displacement has multi-dimensional consequences, affecting the socio-economic structure and the physical environment for refugees in the new settlement (Corsellis \& Vitale, 2005; Scudder \& Colson, 1982). Impacts are different on men, women, and children. The more commitment there is before displacement, the more the grief reaction is the socio-economic consequences affect not merely refugees, but also the hosting society (Scudder \& Colson, 1982; Saarinen, 1976).

Displacement plays a major role in fragmenting families and communities. Although planning is a complex process, it should be done very quickly to be a useful strategic tool in the process of reconstructing displaced communities. Refugee camps planning can influence the way in which refugees reconstruct and develop their communities and reinforce their traditions to help each other (Corsellis \& Vitale, 2005; UNHCR, 2002). The way resettlement occurs, and whether people are displaced as individuals, as families, or even as communities are of great importance. They influence the adaptation of refugees to their new location (Corsellis \& Vitale, 2005; NRC, 2004; Shami, 1993).

\subsubsection{Patterns of Displacement}

The main goal of transitional settlements is to provide a secure, healthy living environment, privacy, and dignity to groups, families, and individuals settled within them. Transitional settlements refer to the camps provided for refugees. They are communities of covered living spaces that may range from emergency responses to durable solutions. High density settlements with large populations are the worst possible alternative for refugees, although refugees might not have the freedom of choice because of the decisions made by the host country, or because of a lack of alternatives (Corsellis \& Vitale, 2005; UNHCR, 2000). Refugee camps usually have two major patterns including an informal one known as dispersed settlements, and a planned formal pattern known as grouped settlements (Corsellis \& Vitale, 2005; Scudder \& Colson, 1982; UNHCR, 2000).

Informal Patterns: Displaced people tend to spontaneously choose dispersed settlements to maintain their independence and sustain themselves, since they are associated with lower security risks. However, such settlements are more prone to tensions with the host community (Corsellis \& Vitale, 2005). Refugees who choose to live in dispersed settlements have the following three alternatives: (1) Dispersed in host families: refugees live with local families or buy land/properties. (2) Dispersed in rural self-settlement: refugees settle on lands owned by groups of locals in rural areas. (3) Dispersed in urban self-settlement: where refugees informally settle in urban areas or occupy unclaimed lands. Planned Formal Patterns: There are three types of formal planned settlements, known as grouped settlements (Corsellis \& Vitale, 2005): (1) Grouped in collective centers: they settle in preexisting buildings including community centers, town halls, or hotels. (2) Grouped in self-settled camps: camps are not managed by any agency. (3) Grouped in planned camps: they stay on site where they are provided with help and services by humanitarian agencies.

UNHCR considers planned settlements the very last resort. This is since these settlements encourage dependency, are more difficult to retreat to than the other settlement alternatives and are more challenging when it comes to achieving durable solutions for population. Consequently, vulnerabilities could be increased to internal and external security concerns (Bonnin, 2012; Corsellis \& Vitale, 2005).

\subsubsection{Planning Issues}

Specialized researchers agree that refugee camps planning must be accomplished at three different levels. First, the strategic level by which transitional settlements are managed on a large scale (regional/national level), mainly dealing with shelters and general needs of refugees. Second, the program level, concerned with the needs of a specific group of refugees. Third, the project level is all about managing the activities of a camp within the physical plan (Corsellis \& Vitale, 2005).

Displaced people usually lose most, if not all, of their livelihood means. Camps should help them regain what they have lost in some form, but complete dependency should be avoided. The support provided to refugees should not 
raise their living standards above that of the local population. Well-planned camps help refugees, as individuals and communities, to manage their lives by regulating the provision of needed resources such as food, water, clothing, and shelter (Bonnin, 2012; Corsellis \& Vitale, 2005).

In such settlements, people act collectively, they depend on each other and, heavily, on external assistance. They create a concentrated consumption to natural resources, in addition to the tensions and conflicts that might arise between refugees and local community, not to mention the de-skilling risk, because of the dependency and overreliance on aid agencies and few competitive work opportunities, and lack of certainty about the future and the time span of the stay (Corsellis \& Vitale, 2005; UNHCR, 2002).

Plots in refugee camps are generally identical in size, usually only residential uses are spatially planned at the block level. It is noted that a camp spatial plan should take into consideration additional physical factors including climate, and topography. The camps' spatial patterns have social, financial, and environmental influences on refugees; they can increase the efficiency of the provided services and infrastructure, and donations delivery (Corsellis \& Vitale, 2005; NRC, 2004; Project, 2004; UNHCR, 1967, 2000).

Over and above, camps should provide spaces for market and commercial facilities, medical services, feeding centers, animal husbandry, food from agriculture, food and non- food distribution centers, education, recreation, child friendly spaces, religious and ritual facilities, and cemeteries and mourning areas (Anderson, 1994; Bonnin, 2012; Corsellis \& Vitale, 2005; Linn, 1983). Camps planning should meet the minimum accessibility standards to the very fundamental livelihood means and services that refugees need. Settlements should be organized in a way that facilitates the process of distribution of food, non-food items, and informative fliers. A distribution system is needed to deliver the items from providers to refugees, emphasizing the avoidance of breakage, and theft risks (Bonnin, 2012; Corsellis \& Vitale, 2005).

Minimum required facilities for refugee camps are site layouts, camps sub-divided sectors, blocks, and standards for provided services. Refugees need flattened roads and paths without obstacles, surface water drainage, water points, sanitation, garbage disposal, and communal washing facilities. Additionally, sufficient lighting in camps is of great importance particularly in dark areas to provide a safe and secure environment. Furthermore, information points are highly recommended so that refugees can get the information they need and raise their concerns regarding the provided services and facilities (Anderson, 1994; Bonnin, 2012; Corsellis \& Vitale, 2005; Linn, 1983).

Well-planned settlements have positive impacts beyond the shelter provision, for they help in strengthening the physical protection and enhance livelihoods, by managing natural resources and minimizing the spread of diseases. However, refugee camps are highly influenced by the provided protection and security facilities, gender, age, and vulnerable groups of refugees (Corsellis \& Vitale, 2005; NRC, 2004; Project, 2004; UNHCR, 1967, 2000). Poor planning of refugee camps might increase the vulnerability of some minorities such as ethnic and elderly people groups. When one attempts to provide protected and secure settlements, fundamental strategies should be considered. First is to reduce vulnerability and exposure to threats. Second is to assure visibility of individuals and groups to protection forces and witnesses. Third is to provide refugees with quality and security enforcement systems of justice. Not to mention the importance of segregating groups, especially when tensions are more likely to happen, by minimizing the chances for communication (Corsellis \& Vitale, 2005; UNHCR, 2002).

Successful refugee camps planning should meet the cultural expectations of refugees to avoid any social disruption. Likewise, conflicts between or within families, clans, and ethnic groups can be avoided or at least reduced (Anderson, 1994; Corsellis \& Vitale, 2005). During the influx of refugees, it is preferred that displaced families live adjacent to people whom they know inside the camp to help them rebuild the sense of their lost community. This is not always possible though, because people arrive over a long period of time. However, it is when the families change their location within the settlement to reside near people whom they know that consolidation of their community occurs (Cernea \& McDowell, 2000; Corsellis \& Vitale, 2005). On the other hand, basing the planning process of the camp around family (one household) leaves no space for individuals who are not part of the family structure and who are left without the protection of the community (Cernea \& McDowell, 2000; Corsellis \& Vitale, 2005; Shami 1993).

\subsubsection{Planning Option and Infrastructure}

Physical Layout: When dealing with refugee camps planning, two key approaches are followed: the grid and the cluster approaches. In the greatly adopted grid approach, a grid of roads is set out; communities and administrative/communal facilities are in the spaces between roads. The grid is very simple to design and mark out. It provides equal access to all plots, and it creates repetitive patterns of rows and plots where shelters are located (Corsellis \& Vitale, 2005; UNHCR, 2002). In the cluster planning approach, a major road infrastructure is 
planned like tree branches with the roads going from central areas used for communal facilities. Hierarchy in roads exists and varied road sizes can be introduced depending on the amount of use (UNHCR 2002; Corsellis \& Vitale, 2005). This approach aims to form decentralized groups of communities, where shelters are grouped together to easily define social units. Cluster planning is preferred because it supports the social communities by introducing private areas, encourages mutual communal activities such as water collection and cooking, and reinforces a social hierarchy which supports acceptance of extension programs (Corsellis \& Vitale, 2005; UNHCR, 2000).

Communities Layout: Corsellis and Vitale (2005) indicated that within settlements, communities are developed according to specific morphological patterns with some alternatives suggested. However, they should be implemented with modifications that meet the specific circumstances and particularities of each case; they should be applied cautiously and with flexibility as follows: (1) Hollow Square Plan: It consists of a public side facing the street, in addition to a private one internal to the square. This square enhances the interaction within families, allowing for solidarity. Moreover, latrines are reserved for families' use, since they are located away from roads, passers-by cannot use them. Yet, fronts of community that face the road led to lack of privacy (Corsellis \& Vitale, 2005; UNHCR, 2002). (2) Straggled Square Plan: The fronts of each community face a cul-de-sac road that is used by residents only, which contributes to maintaining social controls by allowing residents to know their neighbors and improve the community. Rear sides face each other, by which more privacy and security are provided for residents. In addition, lack of long straight roads improves privacy and flexibility, and lessens the funneling of wind which may cause the spread of fire and dust. Latrines in this type of plan are placed away from roads, lest passers-by use them (Corsellis \& Vitale, 2005; UNHCR, 2002). (3) Community Road Plan: In this layout, the front of each community faces a road that widens and narrows, which creates communal spaces linked by streets to improve the sense of community. More privacy is provided because rear sides face each other, and family latrines are built in pairs (Corsellis \& Vitale, 2005).

\subsubsection{Socio-Cultural Influences}

Researchers claim that the main phase of adaptation is when the relocated groups try to recreate the community they lost. It is done through the revival of their rituals and life routines, to cling to their past as a form of nostalgia (Shami, 1993). Throughout the process of displacement, families undergo structural changes such as dispersal, and fission or fusion, and all that might affect individuals' identity and groups' solidarity (Shami, 1993, 2009; Scudder \& Colson, 1982). Since displaced populations usually settle as communities, social ties including families and kinship play the greatest role in the adaptation to the new circumstances. Despite the temporality of the camps, the dynamics between settlers and their settlement will take part in shaping behaviors, spatial configuration, and the way it functions (Corsellis \& Vitale, 2005; Davis, 1978; Fried, 1963; Pryor, 1975; Scudder \& Colson, 1982; Shami, 1993).

Moreover, desires, motivations, and the feelings refugees have, affect their behavior and the morphological spatial patterns. Consequently, the physical milieu and its performance are a result of the interplay between the planned patterns set by the responsible planners and the shifts made spontaneously by the settlers (Corsellis \& Vitale, 2005; Linn, 1983; Rapoport, 1969). Not to mention the fact that settlements' spatial configuration may be a device for social defense. Therefore, types of settlements can be decided by the behavioral patterns of the settlers which are a result of their way of life (Corsellis \& Vitale, 2005; Flanagan, 1990; Rapoport, 1969).

As time goes by, refugees apply changes to adjust their settlement in a way that suits their socio-cultural identity. They make changes to their dwells and the whole settlement to meet the needs of their families and their lifestyles (Al-Homoud, 2003; Corsellis \& Vitale, 2005; Fathy, 1973; Linn, 1983; Lapidus, 1969; Rapoport, 1969). Although the social and cultural values take over all other forces behind adjusting the spatial arrangement, there are other additional forces including age, religion, climate, ceremonial beliefs, defense, and satisfaction (Corsellis \& Vitale, 2005; Linn, 1983; Rapoport, 1969). If the traditions are alive, the shared accepted image of life continues to operate For instance, if the culture dictates the women should live within household compounds, then latrines and the shelter design should meet these traditions. Furthermore, shelter patterns for single women should respect the culture by providing special areas for single women and their dependents (Anderson, 1994; Corsellis \& Vitale, 2005; Rapoport, 1969).

\subsubsection{Behavioral Influence - Defensible Space Theory}

There is a strong association between physical patterns and human behavior. Physical patterns are usually derived from human behavior concepts (Altman, 1980; Al-Homoud, 2010). Thus, there is a key role for the projection of cultural values by non-professional practices on spatial pattern's transformations (Al-Homoud, 2010; Erwin, 1994; Rapoport, 1985). Depending on the context, this association can generate either positive or negative outcomes (Hall, 1966; Jacobs, 1961; Lynch, 1960; Newman, 1973; Rapoport, 1969; Sommer, 1969). Newman defines 
defensible space as "surrogate term for the range of mechanisms- real and symbolic barriers, strongly defined areas of influence, and improved opportunities for surveillance that combine to bring an environment under the control of its residents" (Newman, 1973, p3). Restructuring the spatial pattern of communities allows people to control areas around their shelters. Such spaces increase the sense of community and responsibility even if people do not own the land (Felson; 2002; Newman, 1973; Saarinen, 1976). The physical expressions of the emerging spaces render them as primary or secondary territories (Al-Homoud, 2010; Borchert, 1979; Brown, 1987, Rapoport, 1969, 1985). Attributes if of defensibility include:

1) Territoriality: The fundamental attribute of defensible space theory is territoriality. It provides a variety of spatial options that increase the freedom of space (Altman, 1980; Al-Homoud, 2010). It refers to the capacity of the physical pattern to generate zones of territorial influence. Public space is the focus, through which the physical patterns extend residents' sense of ownership towards public space. The spatial patterns of the settlement create four zones of public spaces: private, semi-private, semi-public, and public zones. Through the configuration of the physical patterns, people extend their sense of responsibility outdoors; hence, they perceive public spaces as semiprivate or private domains (Al-Homoud, 2010; Borchert, 1979; Brown, 1987; Jacobs, 1961; Newman,1973). People take responsibility over such spaces to defend and secure their larger environment. The larger the number of people sharing a territory, the less the control and surveillance over the outdoor space (Jacobs, 1961; Newman,1973).

2) Boundaries Definition: Another key attribute is the clear identification of the territorial zones of influence. Boundaries could be physical elements that distinctly identify the extent of the sphere of influence (Altman, 1980; Appleyard, 1979; Al-Homoud, 2010; Al-Homoud \& Tassinary, 2004; Jacobs, 1961; Newman, 1973; Taylor, 1988; Zeisel, 1981). People take care of areas identified as their own, where they maintain feelings of identity and intruders are easily identified. Clear boundaries definition creates safer environment and strengthens the ties among the community (Al-Homoud, 2010; Jacobs, 1961; Newman, 1973; Tylor, 1988).

3) Natural Surveillance: The third attribute of defensible space theory is natural surveillance. It refers to the capacity of the housing unit design to provide residents with surveillance of the outdoor space. It is done by managing the opportunities of visual connections with the outdoor space (Al-Homoud, 2010; Hall, 1966; Jacobs, 1961; Newman, 1973). When people observe and control public spaces, they render the environment safer and allow enhanced utilization of public areas. Thus, residential units' orientation influences residents' ability to control public areas, especially by directing the openings towards those outdoor spaces (Jacobs, 1961; Newman, 1973).

\subsubsection{Selected Case Studies in Jordan}

The following present two selected case studies in Jordan in the context of spatial planning reflecting the sociocultural impacts:

a. Shift from Planned Formal Pattern - Palestinian Displacement: Al-Hussein Refugee Camp: Of the ten Palestinian refugee camps in Jordan which are: Zarqa, Talibieh, Marka, Souf, Jerash, Irbid, Baqa'a, Husn, and Amman new camp, Al-Hussein camp was selected to be studied in detail in this review. This case presents a formal pattern of displacement; it shows the Palestinian displacement in a planned refugee camp that witnessed socio-spatial shifts by refugees. During the two Arab-Israeli wars of 1948 and 1967, Jordan received the greatest in-flow of Palestinian refugees. In response to the flood of Palestinian refugees in the country, many refugee camps emerged. Al-Hussein camp was one of those camps which was established in 1952. The camp is in the East of the capital Amman, in an area of $421,000 \mathrm{~m}^{2}$. All essential services were provided by UNRWA including education, healthcare, communitybased rehabilitation, and social safety networks. Statistics indicated around 5868 families resided in 2488 shelters in the camp (Al-Homoud et al., 2012; UNRWA, 2012, 2015). The camp is outlined on a grid plan. Ain Jalout Street is the main circulation spine of the camp, representing the core of the streets network and the main commercial spine. The street network provides circulation for both pedestrians and vehicles. The camp has 50 sub-streets connecting the different blocks of the camp. The camp is located on a slope of 35m (Al-Homoud et al., 2012; UNRWA, 2012, 2015). The following reviews two major issues of considerable spatial adaptation mechanisms:

(1) Socio-spatial Adaptation at the Camp Level: Refugees adapted themselves to the situation to fulfill their social, economic, and spiritual needs using the available resources. Refugees created the spaces they needed and modified their housing units. Irregular, random, and large empty lands were created in between the clusters of shelters, where families stemming from the same clan resided, allowing semi-private family activities to take place (Al-Homoud et al., 2012; UNRWA, 2012, 2015). Refugees utilized streets for recreation, creating their own spaces of interests. The elderly enjoys spending their afternoons in front of their homes, escaping the small, enclosed spaces, yet staying close to their families. Streets were also used by women for laundry, and in the afternoons some streets were transformed into private zones, where women met and did some domestic work. Children preferred playing 
on the outdoor stairs of the camp, rather than the gardens and the parks designed for them (Al-Homoud et al., 2012; UNRWA, 2012, 2015).

(2) Physical Adaptation at the Units Level: At the beginning, all refugees had the same shelter unit in the form of a tent. Over time, adaptation to the site became more tangible, and refugees started to add their personal touches to their shelters to distinct themselves by being moderately dissimilar to others. Tents were replaced by single housing units (with temporary ceilings), then permanent ceilings were added, and refugees started expanding vertically. Refugees used the very limited resources they had to color their front facades and decorate their entrances (Al-Homoud et al., 2012; UNRWA, 2012, 2015).

b. Informal Pattern - Circassian Displacement: This case is selected to represent a Circassian informal settlement in the city. The very long process of displacement divided the Circassia families, co-villagers, and kin-groups. Resettlement helped in defining the refugees' identity as immigrants of the mountain people of the Caucasus. Bonds between the immigrants in Jordan were created due to their common experience of relocation which led them to form peasant communities. The context of their settlements played a major role in their inter-group relationships and emphasized their skills as peasants. Concerning their socio-spatial adaptation, their settlement spatial pattern consisted of quarters influenced their social structure. Families belonging to same clan moved together and resided in one of the settlement's quarters. Accordingly, each quarter represented a group of families belonging to the same clan. The borders of each quarter were socially and physically identified, by the cluster of housing units, and even the dead of each quarter (clan) were buried in separate cemeteries (Shami, 2009). Usually the memory of displacement, when invoked, brings out their communities' togetherness to their social or ethnic gatherings. The Circassians struggled in maintaining their ethnic identity in many aspects of their lives: weddings, social gatherings, and daily encounters. They hold tight on their symbols to maintain their collective identity and keep the experiences they went through in history (Shami, 2009).

\section{Method}

The quantitative design attempts to describe the hypotheses of the study, constructs, variables, instrument, population of the study, and sampling techniques and procedures. The quantitative study consisted of a survey utilizing a close-ended structured questionnaire and administered to a random stratified cluster sample of refugees.

Research Design: The study tested the impact of driving engines on the settlement patterns and efficiency of the settlement. After reviewing relevant literature, a structured questionnaire was constructed, and a survey design was utilized to collect the needed data from subjects living at Al-Za'atari camp.

\subsection{Hypotheses of the Study}

(1) Hypothesis 1: Settlement patterns at Al-Za'atari Camp are affected by physical and socio-cultural driving engines. The physical driving engines include improved access to services, improved infrastructure, and microclimate, while the socio-cultural driving engines include safety concerns, cultural concerns, religious reasons, lifestyle, prestige, and ethnicity and origin.

(2) Hypothesis 2: Efficiency of the settlement is affected by physical and socio-cultural driving engines at AlZa'atari Camp. The physical driving engines include improved access to services, improved infrastructure, and micro-climate, while the socio-cultural driving engines include safety concerns, cultural concerns, religious reasons, lifestyle, prestige, and ethnicity and origin.

\subsection{The Variables of the Study}

Following are the quantitative study variables:

The Independent Variable: The driving engines behind the shifted settlement patterns. It is defined by the following sub variables: safety concerns, cultural concerns, religious drivers, lifestyle, prestige, ethnicity and origin, improved infrastructure, improved access to services, micro-climate, and other drivers. These were measured using a dichotomous scale: (1) No, and (2) Yes. Data was collected through the following question which was repeated to all the variables through questions: Did the following factors push you to move your caravan or tent?

1) Safety concerns: It is defined by refugees' sense of protection from risks.

2) Cultural Concern: It is defined by the shared values, social behavior, and heritage of a specific society.

3) Religious Concerns: It is defined by the systematic beliefs, rules, and rituals related to worshiping God with definition of adherence constitutions.

4) Lifestyle: It is defined by attitudes, morals, and tastes that determine people's way of life.

5) Prestige: It is defined by the socio-economic status that led to admiration and distinction from other 
people.

6) Ethnicity and Origin: It is defined by belonging to a social group of shared racial, clan, religious, or lingual backgrounds.

7) Improved Infrastructure: It is defined by the better provision of the basic structures and facilities the community needs to operate including lighting, paths, sewage, garbage disposal, and cleaning.

8) Improved Access to Services: It is defined by the better accessibility to the provided services including education for women and children, medical centers, water and sanitation, and recreation.

9) Micro-climate: It is defined by the specific climate of the local district the subject is living at.

10) Other: It is defined by any other factors that the subjects suggest.

\subsection{Dependent Variables}

1) Dependent Variable 1: Settlement patterns at Al-Za'atari Camp. It is defined as the arrangement of shelters and outdoor spaces within the settlement; clusters with emerging central spaces were described as shifted due to a potential social demand. They were measured using a nominal measure: (1) Linear grid, (2) Shifted-from-grid. Data was collected through the following question: The type of cluster pattern: (1) Linear grid, (2) Shifted-fromgrid.

2) Dependent Variable 2: Efficiency of the settlement, defined by refugees' ability to get their basic needs with minimum wasted resources and efforts. It was measured through the following sub-variables: accessibility to services, provided infrastructure, safety, and communication within the settlement. These were measured a five Point-Likert scale: (1) Strongly Disagree, (2) Disagree, (3) Not Sure, (4) Agree, (5) Strongly Agree, and (0) Not applicable.

a. Accessibility to services: It is defined by facilitated access to the provided services within the cluster including schools, education facilities for women, medical centers, latrines, kitchens, water and sanitation, and recreation. Data was collected through the following questions: Express your satisfaction with the following statements: (1) Sub-1-Schools: My children have easy access to the school in my cluster. (2) Sub-2-Education facilities for Women: Women have easy access to the educational facilities in my cluster. (3) Sub-3-Recreation: I have facilitated access to recreation spaces in my cluster. (4) Sub-4-Medical services: I have facilitated access to medical centers in my cluster. (5) Sub-5-Kitchens: I have facilitated access to public kitchen in my cluster. (6) Sub-6-Latrine: I have facilitated access to public latrines in my cluster.

b. Provided Infrastructure: It is defined by the provision of the basic structures and facilities the community needs to operate including indoor and outdoor lighting, walking paths, sewage, garbage disposal, and cleaning maintenance. Data was collected through the following questions: Express your satisfaction with the following statements: (1) Sub-1-Indoor Lighting: My shelter is provided with the needed indoor lighting. (2) Sub-2-Outdoor Lighting: My shelter is provided with the needed outdoor lighting. (3) Sub-3-Circulation: I am provided with the needed walkable paths. (4) Sub-4-Sewage: My shelter is provided with the needed sewage infrastructure. (5) Sub5-Garbage Disposal: My shelter is provided with the needed garbage disposal. (6) Sub-6-Cleaning Maintenance: My shelter is provided with the needed cleaning maintenance.

c. Safety: It is defined by the sense of protection from risks on both selves and belongings. Data was collected through the following questions: Express your satisfaction with the following statements: (1) Sub-1-Protection of Self and Family: I am able to protect myself and family in my cluster; I ask my neighbors to protect when needed; and I ask my relatives or clan members for protection when needed. (2) Sub-4-Protection of Belongings: I can protect my belongings from violence; I ask neighbors to protect my belongings when needed; and I ask relatives or clan members to protect my belongings when needed.

d. Communication within the settlement: It is defined by the facilitated exchange of information between refugees and the camp mobilizers and/or services' providers, in terms of getting information and raising concerns to mobilizers. They were measured using a five Point-Likert scale: (1) Strongly Disagree, (2) Disagree, (3) Not Sure, (4) Agree, (5) Strongly Agree, and (0) Not applicable. Data was collected through the following questions: Express your satisfaction with the following statements: (1) Sub-1-Getting Information: I get all the information I need from camp mobilizers; I get updates about the information I need frequently; and I know where to go when I need some information. (2) Sub-3-Raising Concerns: I know whom to contact when I need certain information; I know where to go when I need to raise my concerns; I know whom to contact when I need to raise my concerns; and I can raise my concerns to camp mobilizers.

Confounding Variables: The personal information of subjects that might influence the relationships of the study 
including gender, city of origin, length of stay at the camp, number of households in the cluster, number of children in the cluster, number of females, age, education level, and past housing experience. Data was measured as follows:

(1) Gender: (1) Male, (2) Female

(2) City of Origin: (1) Dara'a, (2) Homs, (3) Other.

(3) Length of stay at the camp: (1) less than one month, (2) one month - less than six months, (3) six month - one year, (4) More than one year.

(4) Number of households in the cluster: Number of households in the cluster.

(5) Number of children in the cluster: Number of children in the cluster.

(6) Number of females in the cluster: Number of females in the cluster.

(7) Age: Age: (1) less than 20 years, (2) 20-less than 30, (3) 30-less than 40, (4) 40-less than 50, (5) 50-less than $60,(6)$ More than 60.

(8) Education level: Education level: (1) No education, (2) Primary school, (3) Middle school, (4) Secondary school, (5) higher education.

(9) Past housing experience: (1) Grid, (2) Shifted-from-grid.

\subsection{Instrument - The Questionnaire}

The field survey design was utilized to collect the needed data from subjects in the selected districts of Al-Za'atari Camp. The structured questionnaire consisted of two pages and contained forty-five structured and closed-ended questions written in Arabic. It included a brief about the study, and the actual questions were divided into the following sections: (1) Section One - Personal Information: This section was designed to collect personal information about the subjects that might influence the relationships in the study. (2) Section Two - Settlement Patterns: This section was designed to collect data about the settlement patterns of the cluster. (3) Section Three Driving Engines: This section was designed to collect data about the driving engines behind the shifted settlement patterns. (4) Section Four - Efficiency of the Settlement: This section was designed to collect data about the efficiency of the settlement: Accessibility, Infrastructure, Safety, and Communication.

\subsection{Population of the Study and Sampling Techniques}

The population of the study consisted of refugees at Al-Zaatari Camp, Mafraq, Jordan. According to statistics in 2015 , about 86,040 refugees currently reside in the camp.

Sampling Frame: The sampling frame is taken from maps and statistics of UNHCR, 2015. Al-Za'atari Camp is divided into twelve districts with about 86,040 Syrian refugees in February 2015. Considering the population size in the accessible districts, studied districts were chosen based on the most common planned population size, which was 8000 refugees; therefore, district eleven was excluded. Accordingly, districts five, six, seven, eight, nine and ten were the ones that were included in the sampling frame. Concerning their characteristics, they all had similar population capacity, with an average of $(0.5) \mathrm{km} 2$ area. District eight is the only overpopulated district and has the greatest density, whereas population in district six are almost like what is planned for them. However, district nine has the least population; hence, it is the least dense district.

Sampling Technique: A stratified cluster sampling technique was used as follows: the total number of refugees in the assigned six districts till February 2015, was (44272), with about (117) clusters. A stratified sampling technique was used to select the sample; four subjects were assigned to be selected from each cluster in each of the six districts. Therefore, the total sample size was (468) subjects. Stratification was for representation of each cluster in the assigned districts. The unit of analysis was the head of the household.

Sampling Procedure: Subjects were selected randomly from each of the 117 clusters. The selection system started from Al-Yasmeen Street. The first unit of the first cluster of each district, and in every 15th shelter unit a subject was selected. In cases where the selected subject was not available or refused to be interviewed, it was excluded and substituted by a subject from the next shelter unit. Clusters in each district were surveyed in clockwise sequence and same subjects' selection procedure was followed consistently. Districts five, six, seven, eight, nine and ten were surveyed in sequence. Random selection continued until the sample size of 468 was achieved.

Data Collection Procedures: The survey was conducted as a face-to-face interview using the structured questionnaire in front of the head of the selected household caravan. Visiting time was from Sunday to Thursday, starting at 9 am and ending at $3 \mathrm{pm}$. The average length of the face-to-face interview was 4 to 7 minutes, and the questionnaire was filled by the researcher. The survey started from district five in sequence to the other five districts. 


\section{Results and Discussion}

In the Results section, summarize the collected data and the analysis performed on those data relevant to the discourse that is to follow. Report the data in sufficient detail to justify your conclusions. Mention all relevant results, including those that run counter to expectation; be sure to include small effect sizes (or statistically nonsignificant findings) when theory predicts large (or statistically significant) ones. Do not hide uncomfortable results by omission. Do not include individual scores or raw data with the exception, for example, of single-case designs or illustrative examples. In the spirit of data sharing (encouraged by APA and other professional associations and sometimes required by funding agencies), raw data, including study characteristics and individual effect sizes used in a meta-analysis, can be made available on supplemental online archives.

\subsection{Recruitment}

Provide dates defining the periods of recruitment and follow-up and the primary sources of the potential subjects, where appropriate. If these dates differ by group, provide the values for each group.

\subsection{Descriptive Analysis}

\subsubsection{Demographic Characteristics}

(1) Gender: Refugees who participated in the survey were mainly males, making $63.9 \%$ of the respondents.

(2) Place of origin: Of the study respondents, the vast majority originated from Dara'a (South Syria) and made $73.7 \%$ of the respondents, while $17.5 \%$ originated from Hums (Central Syria), and $8.8 \%$ from other Syrian cities.

(3) Length of Stay: About $92.3 \%$ of the respondents were at the camp for more than one year, while only $0.6 \%$ of them had a stay of less than one month.

(4) Number of Household in the Cluster: The number of households in the cluster ranged between one and seven: $67.9 \%$ of the sample had one household in the cluster, $20.1 \%$ had two households, and about $0.2 \%$ had seven households.

(5) Number of Children: Ranged between zero and twelve; $9.2 \%$ of the sample did not have children, $21 \%$ had three, and $17.3 \%$ had four.

(6) Number of Females in a Household: Of the respondents, $0.9 \%$ did not have females in their families, $29.5 \%$ had one, $28.6 \%$ had two, and $0.2 \%$ had eight.

(7) Age: Respondents under 20 years made $4.3 \%$ of the sample. The most common age was between 30 years and less than 40 , with $37.8 \%$ of the sample, while $4.3 \%$ were below 20 , and $1.9 \%$ were above 60 .

(8) Education Level: Most respondents were educated: illiterates only formed $7.9 \%$ of the sample, $31.4 \%$ attended primary schools, $25 \%$ attended middle school, $25.9 \%$ attended secondary school, and $9.8 \%$ got higher education.

(9) Past Housing Experience: Back in their home country, most of the respondents lived in shifted clusters, while only $29.5 \%$ of them lived within a planned grid pattern.

\subsubsection{Independent Variable 1 - Settlement Patterns}

It can be seen from table 1 that the measure of mean of settlement patterns is $(M=1.68, S D=0.47)$, which is higher than 1.5. This suggests that shifted clusters are more than the grid ones. The settlement patterns are normally distributed with skewness of (-0.78), considering that skewness should be within (-3 and 3). At Al-Za'atari Camp, most respondents $(67.5 \%)$ live within shifted clusters, and the remaining $31.8 \%$ lived within the linear grid settlement pattern.

Table 1. Settlement pattern distribution

\begin{tabular}{llll}
\hline Variables & Mean & Std. Deviation & Skewness \\
\hline Settlement Patterns & 1.68 & 0.47 & -0.78 \\
\hline
\end{tabular}

\subsubsection{Independent Variable 2 - Driving Engines}

Given that 1.5 is the typical center of tendency for either positive or negative confirmation, data distribution of the driving engines can be seen in table 2. From the given measures of central tendencies, positive confirmation for the following driving engines is indicated: Safety concerns $(M=1.55, S D=0.50)$, and improved access to services $(M=1.53, S D=0.50)$. However, the mean measure for the other driving engines, including cultural concerns, 
religious reasons, lifestyle, prestige, ethnicity and origin, improved infrastructure, micro-climate and other is lower than 1.5 , indicating negative confirmation. The lowest mean is achieved for other driving engines $(M=1.11, S D$ $=0.32$ ). Skewness ranges between $(-0.22$ and 1.51$)$; accordingly, driving engines are normally distributed.

Table 2. Driving engines distribution

\begin{tabular}{llll}
\hline Driving Engine & Mean & Std. Deviation & Skewness \\
\hline Safety Concerns & 1.55 & 0.50 & -0.22 \\
Cultural Concerns & 1.31 & 0.46 & 0.83 \\
Religious Reasons & 1.20 & 0.40 & 1.51 \\
Lifestyle & 1.38 & 0.49 & 0.48 \\
Prestige & 1.29 & 0.45 & 0.94 \\
Ethnicity and Origin & 1.26 & 0.44 & 1.09 \\
Improved Infrastructure & 1.48 & 0.50 & 0.09 \\
Improved Access to Services & 1.53 & 0.50 & -0.10 \\
Micro-climate & 1.37 & 0.48 & 0.54 \\
Other & 1.11 & 0.32 & 2.45 \\
\hline
\end{tabular}

Descriptive results showed the following attributes in a decreasing order of their mean measure, as follows:

(1) Safety Concerns: More than half of the sample, making $55.3 \%$ of the respondents, confirmed that safety concerns are a driver for changing the settlement pattern.

(2) Improved Access to Services: Respondents who modified their cluster to have better accessibility to services made $52.4 \%$ of the total sample.

(3) Improved Infrastructure: To $47.6 \%$ of the sample, getting better infrastructure was a driving engine for modifying their cluster, while for $52.4 \%$ it was not.

(4) Lifestyle: For about $61.5 \%$ of the sample, lifestyle was not considered a reason for modifying their clusters.

(5) Micro-climate: Thirty-seven percent of the total sample considered microclimate a driver for changing their settlement pattern, while $63 \%$ disapproved.

(6) Cultural Concerns: Thirty-one percent of the respondents approved that cultural concerns made them to modify their clusters, as opposed to $69 \%$.

(7) Prestige: Most of the study sample disapproved prestige as a driving engine; only $28.8 \%$ said they modified their cluster for this reason.

(8) Ethnicity and Origin: Of the total sample, about one quarter (26.1\%) only confirmed ethnicity and origin as driving engines for the settlement patterns.

(9) Religious Reasons: Of the total sample, only $19.9 \%$ confirmed religious reasons as driving engines for changing the settlement pattern, while the majority $(80 \%)$ denied that.

(10) Other: Only $11.3 \%$ of the respondents mentioned other driving engines that made them modify their cluster. The additional drivers included:

a. Family growth: with new marriages and newborns, the family grows, and more space is needed.

b. Refugees leaving: before leaving the camp refugees either sell or give their caravans to those staying.

c. Donors: Since some caravans are damaged because of weather or fights with other clans, refugees get additional caravans from donors. The damaged caravan in that case is used to extend their new caravan space.

\subsubsection{Dependent Variable - Efficiency of the Settlement}

The total efficiency of the settlement is defined in terms of accessibility, infrastructure, safety, and communication. Positive approval of total efficiency is indicated through the descriptive mean of the total efficiency $(M=2.84$, $S D=0.49$ ), which is greater than 2.5. All the sub-variables showed positive approval, and communication was the 
most positively approved, with a mean value of $(M=3.17, S D=0.87)$, while accessibility was the least, since it achieved the smallest mean value of $(M=2.53, S D=1.07)$. Skewness ranged between $(-0.74$ and 0.04$)$, which indicates that the variables are normally distributed.

Percentiles of the Sub-variables

The following is the percentile for each variable in a decreasing order of their mean measure:

(1) Communication: Descriptive results for each component showed the following:

1.a Getting Information: Only about $10 \%$ of the respondents generally agreed that they get all the information they need from camp mobilizers, while $70.5 \%$ generally disagreed.

1.b Getting Information updates: Of the total sample, about $9.4 \%$ of the respondents generally agreed that they frequently get updates about information they need, while $73.3 \%$ generally disagreed.

1.c Getting Information-place: Only $9.4 \%$ of the respondents generally agreed that they know where to go when they need certain information, while $73.5 \%$ generally disagreed.

1.d Getting Information-contact: Only $11.3 \%$ of the respondents generally agreed that know whom to contact when they need certain information, while $70.5 \%$ generally disagreed.

1.e Raising Concern-place: About $10.2 \%$ of the respondents generally agreed that they know where to go when they need to raise concerns, while $72.5 \%$ generally disagreed.

1.f Raising Concern-contact: About $12.9 \%$ of the respondents generally agreed that they know whom to contact when they need to raise concerns, while $64.7 \%$ generally disagreed.

1.g Raising Concern-mobilizers: About $14.5 \%$ of the respondents generally agreed that they are able to raise concerns to camp mobilizers, while $58.3 \%$ generally disagreed.

(2) Infrastructure: Descriptive results for each component showed the following:

2.a Indoor lighting: Only $16.5 \%$ of the respondents generally agreed that their caravan is provided with the needed indoor lighting, while $55.3 \%$ generally disagreed.

2.b Outdoor Lighting: Of the total sample, $22.2 \%$ of the respondents generally agreed that their shelter is provided with the needed outdoor lighting, while $36.3 \%$ generally disagreed.

2.c Walking Paths: Only $11.4 \%$ of the respondents generally agreed that they are provided with the needed walkable paths, while $63 \%$ generally disagreed.

2.d Sewage: Twenty-two percent of the respondents generally agreed that they are provided with the needed sewage infrastructure in their cluster, while about double that percentage (44.9\%) disagreed or strongly disagreed.

2.e Garbage Disposal: Of the total sample, only $11.7 \%$ generally agreed that they are provided with the needed garbage disposal in their cluster, yet $12.8 \%$ generally disagreed.

2.f Cleaning Maintenance: Only $6.7 \%$ of the respondents generally agreed that they are provided with the needed cleaning maintenance in their cluster, while a majority of $75.8 \%$ generally disagreed.

(3) Safety: Descriptive results for each component showed the following:

3.a Protection of Self and Family: Only $12.2 \%$ of the respondents generally agreed that they are able to protect themselves and their family in their cluster, while $73.1 \%$ generally disagreed.

3.b Protection of Self and Family- neighbors: Of the total sample, $9.7 \%$ generally agreed that they ask their neighbors for protection when needed, while $65.2 \%$ generally disagreed.

3.c Protection of Self and Family- relatives: Respondents who generally agreed that they ask their relatives or clan members for protection when needed made $9.2 \%$, while those who generally disagreed constituted $67.7 \%$.

3.d Protection of Belongings: Only $4.9 \%$ of the respondents generally agreed that they can protect their belongings from violence, yet the majority $(70.1 \%)$ generally disagreed.

3.e Protection of Belongings- neighbors: Only $10.5 \%$ of the respondents generally agreed that they ask neighbors to protect their belongings when needed, while $62.9 \%$ generally disagreed.

3.f Protection of Belongings- relatives: Of the total sample, $11.1 \%$ generally agreed that they ask relatives or clan members for protecting their belongings when needed, while $64.7 \%$ generally disagreed. 
(4) Accessibility: Descriptive results for each component showed the following:

4.a Schools: Only $27.1 \%$ of the respondents generally agreed that their children have easy access to the school in their cluster, while $51.7 \%$ generally disagreed.

4.b Education Facilities for Women: Of the respondents, 31.6\% generally agreed that women have easy access to the educational facilities in their cluster, yet $47.9 \%$ generally disagreed.

4.c Recreation: Only $19.4 \%$ of the respondents generally agreed that they have easy access to recreation spaces, yet about $61.3 \%$ disagreed or strongly disagreed.

4.d Medical Services: Only $18.1 \%$ of the respondents generally agreed that they have easy access to medical services in their cluster, while $48.7 \%$ generally disagreed.

4.e Kitchens: Of the total sample, $41.9 \%$ of the respondents generally agreed that they have easy access to kitchens in their cluster, while $36.1 \%$ disagreed or strongly disagreed.

4.f Latrines: About $36.5 \%$ of the respondents generally agreed that they have easy access to latrines in their cluster, while $40.4 \%$ generally disagreed.

\subsection{Quantitative Analysis - Hypotheses Testing and Discussion}

\subsubsection{Hypothesis 1: Settlement Patterns by Driving Engines}

A multi-nominal logistic regression test and chi-square association were used to test the hypothesis: Settlement patterns at Al-Za'atari Camp are affected by physical and socio-cultural driving engines. The physical driving engines include improved access to services, improved infrastructure, and micro-climate, while the socio-cultural driving engines include safety concerns, cultural concerns, religious reasons, lifestyle, prestige, and ethnicity and origin.

\section{a. Multi-nominal Logistic Regression}

The interactive relationship of the set of driving engines with the settlement pattern is deemed significant as shown in table 3. Significant result is indicated $\left[\chi^{2}(1, N=466)=585.60, \mathrm{P}=0.00\right]$, so it seems that shifted settlement patterns are affected by driving engines at once. The effect of each driving engine is testified in the following section.

Table 3. Multi-nominal logistic regression model - settlement patterns by driving engines

\begin{tabular}{lllll}
\hline Model & -2 Log Likelihood & Chi-Square & df & Sig. \\
\hline Intercept Only & 585.60 & & & \\
Final & 0.00 & 585.60 & 10 & 0.00 \\
\hline
\end{tabular}

\section{b. Chi-square Association Test}

Chi-square test was carried out to test the individual association of each of the driving engines attributes that include safety concerns, cultural concerns, religious reasons, lifestyle, prestige, ethnicity and origin, improved infrastructure, improved access to services, micro-climate, and other driving engines on settlement patterns. Results are displayed in table 4, and presented in a decreasing order of strength, as follows:

Table 4. Chi-square test - settlement patterns by driving engines

\begin{tabular}{|c|c|c|c|c|}
\hline Driving Engine & $\begin{array}{l}\text { Pearson } \\
\text { Chi-Squa }\end{array}$ & $\mathrm{df}$ & $\begin{array}{l}\text { Measures of } \\
\text { Association }(\lambda)\end{array}$ & Exact Sig. (1-sided) \\
\hline Safety Concerns & 270.89 & 1 & 0.60 & 0.00 \\
\hline Cultural Concerns & 98.13 & 1 & 0.00 & 0.00 \\
\hline Religious Reasons & 54.21 & 1 & 0.00 & 0.00 \\
\hline Lifestyle & 136.622 & 1 & 0.07 & 0.00 \\
\hline Prestige & 88.62 & 1 & 0.00 & 0.00 \\
\hline Ethnicity and Origin & 77.08 & 1 & 0.00 & 0.00 \\
\hline
\end{tabular}




\begin{tabular}{lllll}
\hline Improved Infrastructure & 199.00 & 1 & 0.36 & 0.00 \\
Improved Access to Services & 242.23 & 1 & 0.51 & 0.00 \\
Micro-climate & 128.19 & 1 & 0.02 & 0.00 \\
Other & 27.92 & 1 & 0.00 & 0.00 \\
\hline
\end{tabular}

Safety Concerns: Results indicate a significant association between settlement patterns and safety concerns $[\chi 2(1$, $\mathrm{N}=468)=270.89, \mathrm{P}=0.00$ ]. There are two possible justifications for this finding: (1) $90.8 \%$ of the sample have one or more children, and (2) $99.1 \%$ of the sample have one or more females in the household, which might increase their safety concerns. Moreover, most of the sample reflects refugees' safety concerns. This finding is suggested also by the mobilizers in the interviews and confirmed in literature by Corsellis et al. (2005), Linn (1983), and Rapoport (1969).

Improved Access to Services: Results indicate a significant association between settlement patterns and improved access to services $[\chi 2(1, \mathrm{~N}=468)=242.23, \mathrm{P}=0.00]$. About half of the sample were shifting their caravans to get a better access to services. This result is perceived by mobilizers and supported by the visual analysis showing refugees' units being clustered near services creating zones of influence around them.

Improved Infrastructure: Results indicate a significant association between settlement patterns and improved infrastructure $\left[\chi^{2}(1, N=468)=199.00, \mathrm{P}=0.00\right]$. Also, half of the sample felt that they get improved infrastructure when they shift their settlement. This finding is also supported by mobilizers, who indicate that clustering makes refugees stronger to collaborate to get improved infrastructure.

Lifestyle: Results indicate a significant association between settlement patterns and lifestyle $\left[\chi^{2}(1, N=468)=\right.$ 136.62, $\mathrm{P}=0.00$ ]. This finding is supported by Corsellis et al. (2005), Linn (1983), and Rapoport (1969), who indicate that settlements are influenced by residents' lifestyle.

Micro-climate: Results indicate a significant association between settlement patterns and microclimate $\left[\chi^{2}(1, N=\right.$ $468)=128.19, \mathrm{P}=0.00]$. This could be done by moving from one place to another to avoid floods, for example, or by spatially adapting the caravan in ways that limit the negative impacts of the weather, as reported by mobilizers. However, two-thirds did not think of it as a modify factor. Micro-climate as a driving engine for settlement pattern was discussed by Corsellis et al. (2005), Linn (1983), and Rapoport (1969).

Cultural Concerns: Results indicate a significant association between settlement patterns and cultural concerns $[\chi 2$ $(1, \mathrm{~N}=468)=98.13, \mathrm{P}=0.00]$. Qualitative results revealed that privacy is the key cultural concern for refugees and given that $99.1 \%$ of the sample have at least one female, this association makes sense. This finding is supported by Anderson (1994), Corsellis et al. (2005), Rapoport (1969), and mobilizers. On the contrary, two-thirds of the sample did not think of this factor as a modifying factor.

Prestige: Results indicate a significant association between settlement patterns and prestige $\left[\chi^{2}(1, N=468)=\right.$ 88.62, $\mathrm{P}=0.00$ ]. This supports Corsellis et al. (2005), Linn (1983), and Rapoport (1969). However, this aspect is negatively affecting refugees' decision to shift their settlement pattern, about two-thirds of the sample indicated negative effect.

Ethnicity and Origin: Results indicate a significant association between settlement patterns and ethnicity and origin, $\left[\chi^{2}(1, N=468)=77.08, \mathrm{P}=0.00\right]$. Given that $70 \%$ of the sample originates from Dara'a, table 6.2 , they cluster together, as suggested by mobilizers as well. Ethnicity and origin are considered a key driver of refugees' sociospatial adaptation (Corsellis et al., 2005; Davis, 1978; Fried, 1963; Pryor, 1975; Shami, 1993; Scudder, 1976). In contrast, most of the sample perceived that it is not a modifying factor.

Religious Concerns: Results indicate a significant association between settlement patterns and religious concerns, $\left[\chi^{2}(1, N=468)=54.21, \mathrm{P}=0.00\right]$. The large number of mosques found in the camp underscores the importance of the religious aspect. This finding is also confirmed by Corsellis et al. (2005), Linn (1983), and Rapoport (1969). However, most of the sample indicated it was not a driving engine.

Other: Results indicate a significant association between settlement patterns and other driving engines, $\left[\chi^{2}(1, N=\right.$ $468)=27.92, \mathrm{P}=0.00]$. Other driving engines included family growth, refugees leaving, and donations. Also, this factor shows a negative perception.

\subsubsection{Hypothesis 2: Efficiency of the Settlement by Driving Engines}

A linear logistic regression test and one-way ANOVA were used to test the hypothesis: Efficiency of the settlement at Za'atari Camp is affected by physical and socio-cultural driving engines. The physical driving engines include 
improved access to services, improved infrastructure, and micro-climate, while the socio-cultural driving engines include safety concerns, cultural concerns, religious reasons, lifestyle, prestige, and ethnicity and origin.

a. Linear Logistic Regression Test

Results of linear logistic regression test indicate a significant regression model, $[\mathrm{F}(10,457)=6.10, \mathrm{P}=0.00]$. As shown in table 5 all driving engines together affect the total efficiency of the settlement. This is also pointed out by mobilizers who mentioned that the driving engines influence refugees' behavior, which in turn affects the efficiency of the settlement. To test the effect of each driving engine individually.

Table 5. Linear logistic regression model

\begin{tabular}{llllll}
\hline & Sum of Squares & $\mathrm{df}$ & Mean Square & F & Sig. \\
\hline Regression & 13.23 & 10 & 1.32 & 6.10 & 0.00 \\
Residual & 99.15 & 457 & 0.22 & & \\
Total & 112.38 & 467 & & & \\
\hline
\end{tabular}

b. One-way ANOVA

To test the effect of each driving engine on the efficiency of the settlement, one-way ANOVA test was carried out. Results are displayed in table 6, where significant effects are reported in a decreasing order of strength, as follows:

Table 6 . ANOVA test - efficiency by driving engines

\begin{tabular}{llllll}
\hline Components & Sum of Squares & df & Mean Square & F & Sig. \\
\hline Safety Concerns & & & & & \\
Between Groups & 9.12 & 1 & 9.12 & 41.17 & 0.00 \\
Within Groups & 103.25 & 466 & 0.22 & & \\
Total & 112.38 & 467 & & & \\
Cultural Concerns & & & & 10.41 & 0.00 \\
Between Groups & 2.45 & 1 & 2.45 & & \\
Within Groups & 109.92 & 466 & 0.24 & & \\
Total & 112.38 & 467 & & & \\
Religious Reasons & & & & & \\
Between Groups & 1.53 & 1 & 1.53 & & \\
Within Groups & 110.85 & 466 & 0.24 & & \\
Total & 112.38 & 467 & & & \\
Lifestyle & & & & & \\
Between Groups & 2.00 & 1 & 2.00 & & \\
Within Groups & 110.38 & 466 & 0.24 & & \\
Total & 112.38 & 467 & & & \\
Prestige & & & & & \\
Between Groups & 4.37 & 1 & 4.37 & & \\
Within Groups & 108.00 & 466 & 0.23 & & \\
Total & 112.38 & 467 & & & \\
Ethnicity and Origin & 1.09 & 1.09 & & \\
Between Groups & & & & & \\
\hline
\end{tabular}




\begin{tabular}{llllll}
\hline Within Groups & 111.29 & 466 & 0.24 & & \\
Total & 112.38 & 467 & & & \\
Improved Infrastructure & & & & 29.00 & 0.00 \\
Between Groups & 6.58 & 1 & 6.58 & & \\
Within Groups & 105.79 & 466 & 0.23 & & \\
Total & 112.37 & 467 & & 21.67 & 0.00 \\
Improved Access to Services & & & & & \\
Between Groups & 4.99 & 1 & 4.99 & & \\
Within Groups & 107.38 & 466 & 0.23 & & \\
Total & 112.38 & 467 & & & \\
Micro-climate & & & & & \\
Between Groups & 1.35 & 1 & 1.35 & & \\
Within Groups & 111.03 & 466 & 0.24 & & \\
Total & 112.38 & 467 & & & \\
Other & & & & & \\
Between Groups & 1.05 & 1 & 1.05 & & \\
Within Groups & 111.32 & 466 & 0.24 & & \\
Total & 112.38 & 467 & & & \\
\hline
\end{tabular}

Safety Concerns: They have the strongest significant effect on the total efficiency of the settlement, $[\mathrm{F}(1,466)=$ $41.17, \mathrm{P}=0.00]$. This finding is supported by the mobilizers, who indicate that individual families have safety concerns when accessing services that are controlled by clans.

Improved Infrastructure: Significantly affects the total efficiency of the settlement, $[F(1,466)=29.00, P=0.00]$. This is supported by mobilizers. Examples include the random invasion of streets to expand shelter units, as suggested from the visual analysis, in addition to illegal connections to underground networks and building kitchens and latrines without being connected to the sewage network. More than half of the sample responses negatively.

Improved Access to Services: The significantly affect the total efficiency of the settlement, $[\mathrm{F}(1,466)=21.67, \mathrm{P}$ $=0.00]$. According to mobilizers and as indicated by the visual analysis, clustering around services helps clan members access services, yet defers individual families from having facilitated accessibility. Hence, having improved access to services affects the efficieny of the settlement.

Prestige: It significantly affects the total efficiency of the settlement, $[\mathrm{F}(1,466)=18.80, \mathrm{P}=0.00]$, as suggested by mobilizers as well.Some refugees find it difficult to overcome changes to their socio-economic status.

Cultural Concerns: They significantly affect the total efficiency of the settlement, $[\mathrm{F}(1,466)=10.41, \mathrm{P}=0.00]$. Culture affects the way refugees act in their settlement; hence, it is logical to say that culture affects the efficiency of the settlement.

Lifestyle: It significantly affects the total efficiency of the settlement, $[\mathrm{F}(1,466)=8.44, \mathrm{P}=0.00]$, as suggested by mobilizers as well. Refugees' lifestyle in their past experience influences the new lifetyle at the camp.

Religious Reasons: They significantly affect the total efficiency of the settlement, $[F(1,466)=6.42, P=0.01]$. The spiritual need is a significantissue to refugees as indicated by the visual analysis.

Micro-climate: It significantly affects the total efficiency of the settlement, $[\mathrm{F}(1,466)=5.65, \mathrm{P}=0.02]$. In an attempt to adapt to the climatic changes at the camp, refugees apply changes that affect the settlement and its efficiency as a whole, as also suggested by mobilizers. However, refugees negatively perceive micro-climate as a driving engine.

Ethnicity and Origin: They significantly affect the total efficiency of the settlement, $[F(1,466)=4.55, P=0.00]$, as suggested by mobilizers too. 
Other Driving Engines: They significantly affect the settlement, [F $(1,466)=4.41, \mathrm{P}=0.04]$, although it is a driving engine with the least effect. Other driving engines include family growth, refugees leaving, and donations.

\section{Conclusions and Recommendations}

Jordan has a history of providing asylum to refugees. The present exploration is bound to contribute towards planning efficient refugee camps and that is by highlighting the role of refugees' socio-cultural structure in influencing settlement patterns and their efficiency. It could be one of the very few scientific works addressing this issue. Refugee camps last 20 years on average; thus, the study will contribute towards coping with the rapid changes taking place in Al-Za'atari Camp on the long term. Furthermore, the study can benefit similar displacement situations that may take place in the future.

The study explored the morphological settlement patterns at Al-Za'atari Refugee Camp. The raised research inquiries were the following: (1) What are the settlement patterns at Al-Za'atari Camp? (2) What are the driving engines behind the shifted settlement patterns at the camp? It was hypothesized that there was a relationship between the driving engines (physical, social, and socio-spatial), settlement patterns, and the efficiency of the settlement. The quantitative research utilizes a structured questionnaire administered to a random stratified cluster sample of refugees.

Findings revealed two major settlement patterns at the camp: the planned grid, and the shifted-from-grid settlement patterns. The multiple driving engines behind the shifted-from-grid settlement patterns are categorized into three main themes: (1) Social attributes, (2) Physical attributes, and (3) Socio-spatial attributes. It is concluded that shifted-from-grid settlement patterns support refugees by being defensible communities; however, it increases the vulnerability of minorities.

Statistical tests of significance were used to test the hypotheses of the study. Results confirmed the hypotheses of the study. Accordingly, driving engines have significant effects on both the settlement patterns and the total efficiency of the settlement.

\subsection{Relationships Among Research Variables}

Strong types of relationships were found among the study variables that included settlement patterns, efficiency of settlement, and driving engines behind settlement patterns as follows:

Settlement Patterns by Driving Engines: Settlement patterns are affected by the ten driving engines that include safety concerns, cultural concerns, religious reasons, lifestyle, prestige, ethnicity and origin, improved infrastructure, improved access to services, micro-climate, and other driving engines.

Total Efficiency of the Settlement by Driving Engines: Total efficiency of settlement is affected by the ten driving engines that include safety concerns, cultural concerns, religious reasons, lifestyle, prestige, ethnicity and origin, improved infrastructure, improved access to services, micro-climate, and other driving engines.

\subsection{Recommendations for Stakeholders}

Since refugee camp planners' central concern is to achieve the maximum efficiency of settlement, they should consider spatial patterns that cannot be manipulated by refugees. This will avoid strengthening one group at the expense of the other. The following deduced recommendations are directed to the following stakeholders:

Planners: It is recommended to consider refugees' socio-cultural needs in the planning process. According to the exploration, waves of refugees arrive gradually over time; thus, the camp should be expanded in phases instead of one-shot planning process.

Refugee Camps' Officials and Donors: The emerging clustered spaces which were created by refugees can be adapted to generate future spatial patterns. Thereupon, the emerging spatial shifts should be enhanced by integrating the social structure with the spatial system of the settlement. This is considered as an attempt to achieve the planned efficiency of the settlements that are provided for refugees.

\section{References}

ACTED. (2014). Retrieved from http://www.ACTED.org

Al-Homoud, M. (2003). Open Spaces in Old Arab Cities and Recent Changes: A Comparative Analysis. Istanbul: Urban and Environmental Planning and Research Center. Istanbul Technical University.

Al-Homoud, M. (2010). Patterns of Outdoor Territorial Control: a case study of single-family urban housing in Jordan. Architectural Science Review, 184-195. https://doi.org/10.3763/asre.2009.0020

Al-Homoud, M., \& Tassinary, L. (2004). Social Interactions at The Neighborhood-Level as a Function of External 
Space Enclosure. Journal of Architecture and Planning Research, 10-23.

Al-Homoud, M., Abdelhadi, F., \& Jayousi, L. (2012). Syrian Refugee Camps Planning. Housing Planning and Design. Third year Design Studio, Supervisor: Prof. Majd Al-Homoud. Amman: German Jordanian University. Unpublished work.

Altman, I. C. (1980). Culture and Environment. Monterey, CA: Brooks/Cole Publishing Company. https://doi.org/10.1007/978-1-4899-0451-5

Anderson, M. (1994). A UNHCR Handbook: People-oriented Planning at Work: Using POP to Improve UNHCR Programming: A Practical Planning Tool for Refugee Workers. Massachusetts: UNHCR.

Appleyard, D. (1979). The Environment as a Social Symbol: Within a theory of environmental action and perception. American Planning Association Journal, 45, 143-153. https://doi.org/10.1080/01944367908976952

Bajpai, K. (2000). Human Security: Concept and Measurement. Kroc Institute Occasional Papers, 19: OP: 1.

Barutciski, M. (2009). Observation on EXCOM's 60th Session: Does UNHCR Need More EXCOM Conclusions? Refugee.

Bonnin, H. (2012). Accessibility Assessment in Za'atari Refugee Camp. UNHCR: Amman.

Brown, B. B. (1987). Territoriality. In D. Stokols, \& I. Altman (Eds.), Handbook of environmental psychology (pp. 505-531). New York: Wiley.

Cernea, M., \& McDowell, C. (2000). Risks and Reconstruction: Experiences of Resettlers and Refugees. Washington D.C.: The International Bank for Reconstruction and Development / The World Bank. https://doi.org/10.1596/0-8213-4444-7

Colson, E. (1971). The Social Consequences of Resettlement. Manchester: The University of Manchester at The University Press.

Corsellis, T., \& Vitale, A. (2005). Transitional Settlement: Displaced Population. Cambridge. OXFAM GB in association with University of Cambridge.

Council, N. R. (2004). Camp Management Toolkit. Oslo: Norwegian Refugee Council.

Davis, I. (1978). Shelter After Disaster. Oxford: Oxford Polytechnic Press.

Erwin, R. (1994). Lifestyle. Wilson Quarterly, 108-115.

Fathy, H. (1973). Architecture for the Poor. Cambridge: University Press. https://doi.org/10.7208/chicago/9780226239149.001.0001

Felson, M. (2002). Crime and Everyday Life. London: Sage Publications, Inc.

Flanagan, W. (1990). Urban Sociology: Images and Structure. Boston: Allyn and Bacon.

Fried, M. (1963). Grieving for a Lost Gome: Psychological Costs of Relocation. In J. Wilson (Eds.), Urban Renewal: The Record and the Controversy (pp. 359-379). USA: The Massachusetts Institute of Technology and the President and Fellows of Harvard College.

Hall, E. (1966). The Hidden Dimension. USA: Doubleday.

Hansen, C., \& Butzer, K. (1968). Desert and River in Nubia. Madison: The University of Wisconsin Press.

Jacobs, J. (1961). The Death and Life of Great American Cities. New York: Vintage Books.

Lapidus, I. (1969). Middle Eastern Cities. Berkely: University of California Press. https://doi.org/10.1525/9780520323803

Linn, J. (1983). Cities in the Developing World: Policies for Their Equitable and Efficient Growth. London: Oxford University Press.

Liozos, P. (1981). The Heart Grown Bitter: A chronicle of Cypriot War Refugees. Cambridge: Cambridge University Press.

Lynch, K. (1960). The Image of the City. Cambridge MA: MIT Press.

Newman, O. (1973). Defensible Space: Crime Prevention through Urban Design. New York: Macmillan.

Norwegian Refugee Council, International Displacement and Monitoring Center (NRC). (2009). International Displacement: Global Overview of Trends and developments in 2009. Geneva: NRC. 
Olson, M. E. (1979). Refugees as a Special Case of Population Redistribution. In L. A. P. Gosling, \& L. Y. C. Lim (Eds.), Population Redistribution: Patterns, Policies and Prospects, United Nations Fund for Population Activities (pp. 130-152). New York.

Project, S. (2004). Humanitarian Charter and Minimum Standards in Disaster Response. Geneva: Sphere Project.

Pryor, R. (1975). People on the Move: Studies on Internal Migration. London: Methuem and Co. Ltd.

Rapaport, A. (1969). House Form and Culture. New Jersey: Prentice Hall inc.

Rapaport, A. (1985). Thinking about Home Environment. In I. Altman, \& C. Werner (Eds.), Home Environments (pp. 255-285). New York, NY, Plenum. https://doi.org/10.1007/978-1-4899-2266-3_11

Saarinen, T. (1976). Environmental Planning, The Role of the Behavioral Sciences in Environmental Design. New York: Waveland, Inc.

Scudder, T., \& Colson, E. (1982). Involuntary Migration and Resettlement. Boulder: Westview Press.

Shami, S. (1993). The Special Implications of Population Displacement and Resettlement: An Overview with a Focus on The Middle East. Amman: Yarmouk University. https://doi.org/10.2307/2546699

Shami, S. (2009). Historical Process of Identity Formation: Displacement, Settlement, and Self-Representation of the Circassians in Jordan. Iran and Caucas, 13, 141-160. https://doi.org/10.1163/160984909X12476379008160

Sommer, R. (1969). Personal Space: The Behavioral Basis of Design. NJ: Prentice-Hall.

Tylor, R. (1988). Human Territorial Functioning (pp. 166-197). Cambridge University Press.

UNHCR. (1967). Convention and Protocol Relating the Status of Refugees. Geneva: UNHCR.

UNHCR. (2000). Handbook for Emergencies. Geneva: UNHCR.

UNHCR. (2002). Environmental Consideration in the Life Cycle of a Refugee Camp. Draft 2.2. Geneva: UNHCR.

UNHCR. (2014). Syrian Regional Response Plan. UNHCR, Jordan.

UNHCR. (2015). http://www.unhcr.org. Accessed October-February 2015/2016

UNRWA. (2012). https://www.unrwa.org. Accessed October-February 2015/2016. https://www.unrwa.org/wherewe-work/jordan/husn-camp

UNRWA. (2015). https://www.unrwa.org. Accessed October-February 2015/2016. https://www.unrwa.org/wherewe-work/jordan/husn-camp

Woods, R. (1982). Theoretical Population Geography. London and New York: Longman.

Zeisel, J. (1981). Inquiry by Design. Monterey, CA: Brooks/Cole.

\section{Copyrights}

Copyright for this article is retained by the author(s), with first publication rights granted to the journal.

This is an open-access article distributed under the terms and conditions of the Creative Commons Attribution license (http://creativecommons.org/licenses/by/4.0/). 